\title{
Parturition premature imminens management : A review
}

\section{article}

\author{
Nanda Rachmad Putra Gofur ${ }^{\mathrm{a}}$, Aisyah Rachmadani Putri Gofur ${ }^{\mathrm{b}}$, Soesilaningtyas ${ }^{\mathrm{c}}$, \\ Rizki Nur Rachman Putra Gofur ${ }^{\mathrm{d}}$, Hernalia Martadila Putrie, \\ ananda.rachmad.gofur@ vokasi.unair.ac.id

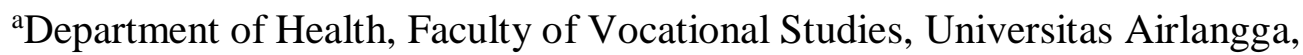 \\ Dharmawangsa Dalam Selatan 28-30, Surabaya 60286, Indonesia \\ ${ }^{b}$ Faculty of Dental Medicine, Universitas Airlangga, Mayjen Prof. Dr. Moestopo No.47, \\ Surabaya 60132, Indonesia \\ ${ }^{3}$ Department of Dental Nursing, Poltekkes Kemenkes, Pucang Jajar Tengah No.56, \\ Surabaya 60282, Indonesia \\ ${ }^{4}$ Faculty Of Medicine, Universitas Airlangga, Mayjen Prof. Dr. Moestopo No.47, \\ Surabaya 60132, Indonesia \\ ${ }^{5}$ Narizma Healthcare, Krukah Timur no. 9, Surabaya 60284, Indonesia \\ Corresponding email: nanda.rachmad.gofur@vokasi.unair.ac.id. Nanda Rachmad Putra \\ Gofur \\ Department of Health, Faculty of Vocational Studies, Universitas Airlangga, Surabaya, \\ Indonesia
}

\begin{abstract}
Introduction : Parturition Premature Imminens (PPI) or the threat of premature birth is the presence of uterine contractions accompanied by cervical changes in the form of dilatation and effacement before 37 weeks of gestation and can cause premature birth. Premature birth is a problem with a high prevalence in the world and is a challenge for doctors, especially obstetricians, to find out the causes and prevention of premature birth. The main problem with premature birth is the lack of success in its managemen. Discussion : The mechanism of preterm labor is not different from that of term labor, namely uterine contractility, cervical ripening, and membrane rupture. The fundamental difference is that the activation process in term labor is part of the physiological activation, whereas in preterm labor it is pathological. The usual path of delivery can be seen based on anatomy, biochemistry, immunology, endocrinology, and clinical symptoms. Prevention should be done in PPI management, as Performed prenatal care, diet, administration of vitamins, hygiene, Activity (work, coitus) is restricted in patients with a history of preterm labor, Immediate treatment if there is infection or comorbidities, Abdominal surgery and dental procedures are postponed until delivery. Special condition as Patients with multiple pregnancies should be on bed rest from the 28th to the 36th week. Fibromyoma, if there are complaints, can be treated with bed rest and analgesics. Surgery is avoided as much as possible. Placenta previa is treated with complete bed rest and blood transfusions to delay the birth of the baby until it is viable. Incompetent cervix should be sutured in the first part of the second trimester as long as all requirements are met. Elective SC and repeat is only done if it is believed that the baby is old enough. Medicines can be used to stop labour. Conclusion : In general, the management of preterm labour includes the administration of a single dose of corticosteroid in women 24-34 weeks' gestation with a risk of delivery within 7 days. In addition, magnesium sulphate can reduce the severity and risk of cerebral palsy in infants when born before 32 weeks of gestation. First-line tocolytics such as beta adrenergic agonists, calcium channel blockers, NSAIDs can be given for prolongation of pregnancy up to 48 hours (administration of antenatal steroids).
\end{abstract}

\section{Keywords : PPI, Management, birth, Disease}




\subsection{Introduction}

Parturition Premature Imminent (PPI) or the threat of premature birth is the presence of uterine contractions accompanied by cervical changes in the form of dilatation and effacement before 37 weeks of gestation and can cause premature birth. Premature birth is a problem with a high prevalence in the world and is a challenge for doctors, especially obstetricians, to find out the causes and prevention of premature birth. The main problem with premature birth is the lack of success in its management (Hanger et al, 2016).

ACOG defines preterm birth as delivery that occurs between the gestational age of more than 20 weeks and less than 37 weeks from the first day of the last menstrual period. The POGI Geomaterial Medical Association in Semarang in 2005 determined that preterm labour is delivery that occurs at 22-37 weeks of gestation. According to Wibowo (1997), preterm labour is regular uterine contractions after 20 weeks of gestation and before 37 weeks, with contraction intervals of 5 to 8 minutes or less and accompanied by one or more of the following signs: (1) progressive cervical changes (2) cervical dilation of 2 centimetres or more (3) cervical effacement 80 percent or more (Cook et al, 2000; Hanger et al, 2016).

Preterm delivery is defined as delivery that occurs at less than 37 weeks' gestation after being considered viable. Preterm labour can be caused by maternal, fatal, paternal, environmental, and genetic factors. The mechanism of preterm labour is no different from term delivery. Prediction of preterm labour can be done by examining cervical length with transvaginal ultrasonography, fatal fibronectin, and IGF binding protein-1 or placental alphamicroglobulin-1 (PAMG-1). In infants born prematurely, the morbidity and mortality rates increase due to the immaturity of the body's organs, especially in infants born weighing $<2500$ grams. Anoxia and respiratory distress (RDS) are also more common in infants born prematurely (Abbassi-Ghanavati, 2009).

Aetiology of PPI might Iatrogenic and Spontaneous. The Gestational age might between Preterm (32-36 weeks), Very preterm (28-32 week) and Extremely preterm (20-27 weeks). Baby's birth weight might variance between LBW (1500-2500 gr), LBW (1000-1500 gr) and BBLER (<1000 gr) (Cook et al, 2000; Abbassi-Ghanavati et al, 2009) . Aim of this study is to understand management of Parturition Premature Imminent.

\subsection{Discussion}

The mechanism of preterm labour is not different from that of term labour, namely uterine contractility, cervical ripening, and membrane rupture. The fundamental difference is that the activation process in term labour is part of the physiological activation, whereas in 
preterm labour it is pathological. The usual path of delivery can be seen based on anatomy, biochemistry, immunology, endocrinology, and clinical symptoms. Activation of uterine components can be synchronous and asynchronous. Synchronous activation will lead to spontaneous preterm labour; whereas asynchronous activation gives rise to different phenotypes. For example, membrane activation causes preterm PROM, cervical activation causes cervical insufficiency, and myometrial activation causes preterm uterine contractions (Word et al, 2007; Agrawal V dan Hirsch 2012).

Aetiology and Risk Factors divided into 2, namely, Iatrogenic consist of Mother's condition, as Severe preeclampsia and eclampsia, Antepartum haemorrhage (placenta previa and placental abruption), Chorioamnionitis and Severe heart disease or severe lung/kidney disease. Second, Fatal state are Fatal distress. (anaemia, hypoxia, acidosis or fatal heart failure), Intrauterine infection, Fatal growth retardation (IUGR), Rhesus isoimmunization. Cord entanglement in monochorionic twins (van der Burg B dan van der Saag 1996).

Spontaneous happen due to many risk factors, as Idiopathic, Pregnancy history (prematurity, premature rupture of membranes), The distance between pregnancies is too close, Premature rupture of membranes, Cervical incompetence, Placental insufficiency, Uterine overdistention and Pregnant with twins. Trimester bleeding, Uterine abnormalities, Trauma, Medical disease as Hypertension, SLE, Restrictive lung disease, Hyperthyroid, DM, Heart and kidney disease, Hydramnios, and Congenital abnormalities. Other factors such as Low socioeconomic, Smoke, Infection, Poor antenatal care is also risk factor for PPI (Herb and Nilson 2006).

In establishing a diagnosis, it is necessary to carry out several stages, including: History: gestational age, risk factors, Early symptoms of PPI, Signs of PPI, Creasy and Heron's Criteria. Uterine contractions $4 \mathrm{x}$ in 20 minutes accompanied by one of the following conditions, Rupture of the amniotic sac, Opening $>2 \mathrm{~cm},>50 \%$ depletion, Vaginal duh increase and Cervical changes (Romero et al, 2006).

\subsubsection{Criteria and Prevention}

Based on 1997 ACOG Criteria, consist of Contractions that occur with a frequency of four times in 20 minutes or eight times in 60 minutes plus progressive changes in the cervix, Cervical dilatation of more than $1 \mathrm{~cm}$, and Cervical effacement of $80 \%$ or more. Based on Criteria Mansoor, Regular uterine contractions at least every 3 to 5 minutes for 45 seconds for at least 2 hours, In the active phase, the intensity and frequency of contractions increase as the patient performs activities. Ask and look for symptoms that include major and minor risk factors, Gestational age between 20 to 37 weeks, Estimated fatal weight $\underset{w w w . i j p p . o r g}{\text { according to }}$ 
gestational age between 20 to 37 weeks. Abnormal fatal presentation is more common in PPI (Yosidha et al, 2002; Meneguel et al, 2003).

Prevention should be done in PPI management, as Performed prenatal care, diet, administration of vitamins, hygiene, Activity (work, coitus) is restricted in patients with a history of preterm labour, Immediate treatment if there is infection or comorbidities, Abdominal surgery and dental procedures are postponed until delivery. Special condition as Patients with multiple pregnancies should be on bed rest from the 28th to the 36th week. Fibromyoma, if there are complaints, can be treated with bed rest and analgesics. Surgery is avoided as much as possible. Placenta previa is treated with complete bed rest and blood transfusions to delay the birth of the baby until it is viable. Incompetent cervix should be sutured in the first part of the second trimester as long as all requirements are met. Elective SC and repeat is only done if it is believed that the baby is old enough. Medicines can be used to stop labor (Ganchimeg et al, 2012)

\subsubsection{Management of PPI :}

Management in cases of imminent preterm labour can be in the form of conservative management and termination. Indications for Conservative Management, if (Despandhe et al, 2013):

- Gestational age 24-34 weeks

- Dilation $<3 \mathrm{~cm}$

- No intrauterine infection, preeclampsia, or active bleeding

- No fatal distress

- intact membranes

Indications for Termination Management, if (Despandhe et al, 2013):

- Gestational age $<24$ weeks or $>34$ weeks

- Dilation $>3 \mathrm{~cm}$

- There are signs of intrauterine infection, preeclampsia, or active bleeding

- There is fatal distress

- IUFD

- IUGR

- ruptured membranes

1.2.2.1 Conservative management (Crane et al, 2008; Kumari et al, 2017) :

o Total bed rest 
o Hydration

1.2.2.2. Pharmacology (Crane et al, 2008; Kumari et al, 2017) :

o TOCOLITIK

- Given within the first 48 hours

- Nifedipine (initial $20 \mathrm{mg}$, followed by $3 \times 10 \mathrm{mg}$ ) orally

- 2-agonist

- Terbutaline sulphate $1000 \mathrm{~g}$ (2 ampoules) in $500 \mathrm{ml} \mathrm{NaCl} 0.9 \%$ until the contractions disappear

- Salbutamol $10 \mathrm{mg}$ IV in 1 litter of $0.9 \% \mathrm{NaCl}$ until contractions disappear

- $\quad$ MgSO4 4-6 g IV

o Corticosteroids

- Lung maturation

Dexamethasone $6 \mathrm{mg}$ IM every 12 hours 4 times

Betamethasone $12 \mathrm{mg}$ IM every 24 hours twice a day

o ANTIBIOTICS (prophylaxis)

Ampicillin 2 g IV every 6 hours

- Penicillin G 2 million units IV every 6 hours

- Clindamycin 3x300 mg PO for 7 days

\subsection{Conclusion}

In general, the management of preterm labour includes the administration of a single dose of corticosteroid in women 24-34 weeks' gestation with a risk of delivery within 7 days. In addition, magnesium sulphate can reduce the severity and risk of cerebral palsy in infants when born before 32 weeks of gestation. First-line tocolytics such as beta adrenergic agonists, calcium channel blockers, NSAIDs can be given for prolongation of pregnancy up to 48 hours (administration of antenatal steroids).

\subsection{References}

Abbassi-Ghanavati M, Greer LG, Cunningham FG. Pregnancy and laboratory studies: a reference table for clinicians. Obstet Gynecol. 2009;114(6):1326-31.

Agrawal V, Hirsch E. Intrauterine infection and preterm labour. Semin Fatal Neonatal Med. 2012;17(1):12-19

Cook JL, Zaragoza DB, Sung DH, Olson DM. Expression of myometrial activation and stimulation genes in a mouse model of preterm labour: Myometrial activation, stimulation, and preterm labour. Endocrinology. 2000;141(5):1718-28.

Crane JMG, Hutchens D. Transvaginal sonographic measurement of cervical length to predict preterm birth in asymptomatic women at increased risk: A systematic review. Ultrasound Obstet Gynecol Off J Int Soc Ultrasound Obstet Gynecol. 2008;31(5):579-87.

Deshpande SN, van Asselt ADI, Tomini F, Armstrong N, Allen A, Noake C, et al. Rapid fetal fibronectin testing to predict preterm birth in women with symptoms of premature 
labour: A systematic review and cost analysis. Health Technol Assess Winch Engl. 2013;17(40):1-138.

Ganchimeg T, Ota E, Morisaki N, Laopaiboon M, Lumbiganon P, Zhang J, et al. Pregnancy and childbirth outcomes among adolescent mothers: A World Health Organization multicountry study. BJOG Int J Obstet Gynaecol. 2014;121(Suppl 1):40-8.

Hanger P, Karalee A, Disbud N. Our experience of nifedipine as a tocolytic agent in preterm labour (24 weeks to 36 weeks 6days). Int $\mathrm{J}$ Reprod Contracept Obstet Gynecol. 2016;6(2):636

Herbst A., Nilsson C. Diagnosis of early preterm labour. BJOG. 2006;113(Suppl. 3):60-7.22.Brazilian Neonatal Research Network. Antenatal corticosteroid use and clinical evolution of preterm new-born infants. J Pediatr. 2004;80(4):277-84.

Kumari A, Saini V, Jain PK, Gupta M. Prediction of delivery in women with threatening preterm labour using phosphorylated insulin-like growth factor binding protein-1 and cervical length using transvaginal ultrasound. J Clin Diagn Res JCDR. 2017;11(9):QC01 QC04.

Meneguel JF, Guinsburg R, MiyoshiMH, Peres CA, Russo RH, Kopelman BI, Camano L. Antenatal treatment with corticosteroids for preterm neonates: impact on the incidence of respiratory distress syndrome and intra-hospital mortality. Sao Paulo Med. J. 2003;121(2):45-52.

Romero R, Espinoza J, Kusanovic JP, Gotsch F, Hassan S, Erez O, et al. The preterm parturition syndrome. BJOG Int J Obstet Gynaecol. 2006;113(Suppl 3):17-42.

van der Burg B, van der Saag PT. Nuclear factor-kappa-B/steroid hormone receptor interactions as a functional basis of anti-inflammatory action of steroids in reproductive organs. Mol Hum Reprod. 1996;2(6):433-8.

Word RA, Li XH, Hnat M, Carrick K. Dynamics of cervical remodeling during pregnancy and parturition: Mechanisms and current concepts. Semin Reprod Med. 2007;25(1):69-79.

Yoshida M, Sagawa N, Itoh H, Yura S, Takemura M, Wada Y, et al. Prostaglandin $\mathrm{F}$ (2alpha), cytokines and cyclic mechanical stretch augment matrix metalloproteinase-1 secretion from cultured human uterine cervical fibroblast cells. Mol Hum Reprod. 2002;8(7):681-7. 